\title{
LES ELEMENTS DE SYNTAXE STRUCTURALE DE L. TESNIÈRE ET LA GRAMMAIRE SLOVENE
}

C'est au cours de mes études de slavistique (1947-1952) que je me suis familiarisé avec l'oeuvre de L. Tesnière, tout d'abord grâce à ma lecture de son livre Oton Joupantchich, poète slovène. ' Je l'ai retrouvé plus tard lorsque j'entrepris l'examen de son importante monographie sur le duel en slovène ${ }^{2}$ voulant esquisser une histoire exhaustive des dialectes slovènes pour M. Vasmer $(1962) .{ }^{3}$ Ma troisième rencontre avec l'oeuvre de Tesnière est liée au compte rendu que j'ai fait de l'Essai de grammaire slovène par $\mathrm{Cl}$. Vincenot (Slavistična revija 1979); ${ }^{4}$ ceci m'a amené à parcourir les Eléments de syntaxe structurale (éd. $1959^{5}$ - l'influence de Tesnière sur le travail de Vincenot étant très sensible). En préparant le présent exposé, je me suis appuyé essentiellement sur la version russe des Eléments (Osnovy strukturnogo sintaksisa, $1988,{ }^{6}$ celle-ci se réfère à la $2^{\text {ème }}$ édition parue en 1976 et raccourcie d'un septième).

Ma Grammaire slovène de $1976^{7}$ se rapproche, en de nombreux points, des conceptions que Tesnière avait exposées dans son oeuvre (Eléments de syntaxe structurale), malgré le fait que je ne l'avais pas encore lue. L'influence de Tesnière fut indirecte et procéda par le biais du projet d'une nouvelle grammaire de la langue

1 Oton Joupantchich, Poète Slovène, l'homme et l'oeuvre, Paris, 1931, $15+383$ pp.

2 Les Formes du duel en slovène, Paris, 1925, $20+454 \mathrm{pp}$; Atlas pour servir à l'étude du duel en slovène, Paris, $40 \mathrm{pp}+70$ cartes $+4 \mathrm{pp}$.

3 Die slovenische Dialektforschung, Zeitschrift für slavische Philologie 30 (1962), $\mathbf{N}^{\circ} 2$, pp. 283-414. - En version slovène élargie dans mon livre Portreti, razgledi, presoje, K zgodovini slovenskega jezikoslovja ob 400-letnici Trubarjeve smrti, Maribor, Založba Obzorja, 1987: Slovensko narečjeslovje, pp. 217-256; sur Tesnière 241 pp.

4 Poskus slovenske slovnice C. Vincenota, l. c., pp. 262-292, 486-496. - Une partie de ce texte a été réimprimé sous le titre Une syntaxe tesniérienne de la langue littéraire slovène dans mon livre Nova slovenska skladnja, Ljubljana, DZS, 1982, pp. 262-292. - Le titre de la grammaire de Claude Vincenot: Essai de Grammaire Slovène, Ljubljana, Mladinska knjiga, 1975, 24 + 353 pp.

5 Préface de Jean Fourquet, $2^{\text {ème }}$ édition revue et corrigée, $26+671 \mathrm{pp}+(\mathrm{I})$ carte.

6 Osnovy strukturnogo sintaksisa / Ljus'en Ten'er, perevod s francuzskogo I. M. Boguslavskogo, L. I. Luht, B. P. Narumova, S. L. Sahno, Moskva, Progress, 1988, 653 pp.

7 Jože Toporišič, Slovenska slovnica, Maribor, Založba Obzorja, 1976, 588 pp. - "Edition revue et élargie" ibidem, 1984, 739 pp (la réimpression de cette $2^{\text {ème }}$ édition en 1991). 
littéraire tchèque, ${ }^{8}$ notamment pour ce qui concerne mon adhésion à la catégorie de valence (vezljivost en slovène) et en même temps aux catégories du propositionnel et du modificateur. La valence se trouve d'ailleurs au centre des préoccupations de Tesnière lorsqu'il traite des problèmes syntaxiques.

Quels sont donc les rapports entre les Eléments de Tesnière et ma propre Grammaire?

Un premier rapprochement est sensible dans la conception des classes de mots. La tradition dans le domaine de la théorie linguistique chez nous était peu satisfaisante pour moi, c'est pourquoi j'ai choisi le rôle syntaxique primaire (des parties de la phrase) comme critère classificateur des classes de mots. Dans mon ouvrage Langue littéraire slovène 1 (1965), ${ }^{9}$ j'avais déjà réuni, dans une même classe de mots adjectivaux, les adjectifs traditionnels, les participes déclinables (pričujoč = étant présent, obledel = déteint, tepen $=$ battu, $u$ bit $=$ tué), les numéraux et pronoms adjectivaux (p. 186: "mots adjectivaux"). C'est ainsi que les numéraux (pét, pêti, peter $-a$-o, petero, peteren) sont devenus des adjectifs numéraux, les participes adjectifs participaux etc. appelés autrement par tradition (pronoms adjectivaux). Les pronoms deviennent désormais (cf Langue littéraire slovène 2,1966$)^{10}$ des espèces de sous-ensembles dans le cadre du substantif, de l'adjectif et de l'adverbe: "Les mots pronominaux remplacent des substantifs, des adjectifs et des adverbes déterminés par le contexte ou la situation de communication" (1. c. 127). Plus tard, ${ }^{11}$ j'ai traité de la même façon les pronoms substantivaux en tant que sous-ensemble du mot substantival, bien que je considère comme pronoms (particuliers) jaz (je, moi) et $t i$ (tu, toi); comparez au génitif mene - me $=n j e g a-g a$ (de moi $=$ de lui). - Tout ceci correspond parfaitement à l'analyse que Tesnière réserve aux classes de mots, $p$. ex. celle des noms en substantifs particuliers et substantifs généraux. Cependant, j'ai rangé, en 1974, parmi les classes de mots à sens plein également les participes passés en $-l$ et $-n /-t$ en tant que prédicatifs. ${ }^{12}$

Parmi les mots grammaticaux je distingue aussi, de façon très nette, l'interjection (medmet) ${ }^{13}$ et la particule (členek). ${ }^{14}$ Chez Tesnière, on retrouve les deux classes de

8 Vedecká synchronní mluvnice spisovné češtiny, Zakladná koncepce a problemy, Praga, 1974, pp. $1-38$.

9 Slovenski knjižni jezik 1, Maribor, Založba Obzorja, 1965, 236 pp.

10 Slovenski knjižni jezik 2, Maribor, Založba Obzorja, 216 pp.

11 Kratko oblikoslovje slovenskega knjižnega jezika, Seminar slovenskega jezika, literature in kulture, Informativni zbornik, Ljubljana, 1974, pp. 29-50; Besednovrstna vprašanja slovenskega knjižnega jezika, Jezik in slovstvo 20 (1974/75), pp. 33-39; Slovenske zaimenske besede, ibid, pp. 117-119; Esej o slovenskih besednih vrstah, ibid, pp. 295-305 (paru aussi dans: Referati od X zasedanie na meǵunarodnata komisija za izučavanie na gramatička struktura na slovenskite jazici, Skopje, 1979, pp. 41-51; et dans: Nova slovenska skladnja, Ljubljana, DZS, 1982, pp. 321-334.

12 Les prédicatifs peuvent connaître uniquement la motion nominative en genre et en nombre, p. ex.: delal $-a-o$, delala $-i-i$, delali - $e-a$. A comparer aussi avec Povedkovniß̌ke besedne zveze (Nova slovenska skladnja), 1982, pp. 113-118. 
mots dans sa notion de mot-phrase, alors que la particule apparaît également dans le chapitre sur l'adverbe (classe particulière).

Je considère aussi que la conjonction de coordination devance la conjonction de subordination, laquelle, à son tour, devance la préposition: Vem, pa ne povem- Čeprav vem, ne povem - Kljub vedenju ne povem (Je sais, mais ne le dirai point - Bien que je le sache, je ne le dirai point - Malgré ma "connaissance de la question" je n'en dirai rien).

En ce qui concerne la valence (que j'ai introduite dans la slovenistique avec l'édition de 1975/76), ${ }^{15}$ ma Grammaire ${ }^{16}$ diffère des Eléments dans le point particulier du passif où l'identité du second actant est conservée, et que celle du prime actant subit des changements sans que pour autant A2 devienne A1 comme c'est le cas chez Tesnière: Ančko (A2) so starši (A1) pohvalili = Ančka (A2) je bila od staršev (C) pohvaljena [Les parents (A1) ont loué Annette (A2) = Annette (A2) a été louée par les parents (C)]. Néanmoins, j'applique la notion de valence au-delà de la relation actif-passif, dans le cadre des circonstants (p. ex. vstopiti $v$ razred - entrer dans la classe) et des translations: Oče prihaja - prihod očeta - očetov prihod (le père arrive, l'arrivée du père), etc.

Je distingue les translations dans le cadre des classes de mots de celles qui interviennent au niveau syntaxique, p. ex. (oče) nje - njen (oče) (le père à elle - son père) en opposition avec p. ex. majhno dekle - dekletce (petite fille - fillette), ou il y a une différence nette entre la locution (base d'énoncé) et le mot dérivé.

La syntaxe de ma Grammaire est loin de négliger la catégorie du mode, elle réserve une place relativement importante à la division en thème et rhème, et inclut également la phonétique phrastique: le découpage en syntagmes suivis de pauses, l'intonation de la phrase et son centre, ainsi que le registre, la vitesse du débit, et le ton (coloris). Elle n'hésite pas, pour ce qui concerne l'ordre des mots et l'ordre des propositions, à sortir du cadre de l'énoncé (et ceci en partie dès l'étude syntaxique de ce dernier) pour toucher à la question du paragraphe textuel.

13 Je précise que les "formes impératives" traditionnelles comme ná náte (náta) - Tiens! Tenez! représentent pour moi des verbes défectifs, réduits à la seule forme de l'impératif.

14 Pour cette classe de mots cf. surtout mon étude Stavčni ustrezniki členkov, Seminar slovenskega jezika, literature in kulture 27, Ljubljana, 1991, pp. 3-16.

15 Pomenski ustroj stavka, Jezik in slovstvo 21 (1975/76), pp. 213-222.

16 Slovenska slovnica $1976(1984,1991)$, le chapitre ayant pour titre Upovedovanje, p. 423 (propozicija - proposition), pp. 290-293 (prehodnost - transitivité), pp. $472-473$ (glagolska fraza phrase verbale); cf. plus particulièrement Nova slovenska skladnja, 1982, pp. 83-113 (Glagolske besedne zveze - locutions verbales). 


\section{Povzetek}

\section{TESNIÈRJEVE OSNOVE STRUKTURNE SKLADNJE IN SLOVENSKA SLOVNICA}

$Z$ delom L. Tesnièrja sem se najprej seznanil, ko sem kot študent slavistike (1947-1952) bral njegovo knjigo Oton Joupantchitch, le poète slovène, zatem pa, ko sem za M. Vasmerja podal obširno zgodovino slovenske dialektologije (1962) in sem pri tem pregledoval njegovo veliko delo o dvojini v slovenščini. Tretjič sem se srečal s Tesnièrjevim delom, ko sem, ocenjujoč knjigo C. Vincenota Essai de grammaire Slovène (Slavistična revija 1979), listal po njegovih Eléments de syntaxe structurale (izdaja 1959 - Vincenot se namreč močno opira na Tesnièrja). Ko sem pripravljal pričujoči referat, sem v glavnem gledal v ruski prevod Tesnièrjeve knjige (Osnovy strukturnogo sintaksisa, 1988, ki se opira na drugo izdajo Tesnièrjeve Knjige, 1976, obsegovno skrajšan prevod za eno sedmino obsega).

Slovenska slovnica 1976 je v marsičem blizu tesnièrjevskim pogledom v ESS, vendar je jaz dotlej nisem poznal. Je pa na mojo slovnico vplivala posredno preko načrta za novo slovnico češkega knjižnega jezika (v moji SS 1976 citirana: Vedecká sinchronní mluvnice spisovné češtiny, Základna koncepce a problemy, Praga, 1974, 1-38), in sicer prav $v$ zvezi $z$ mojim prevzemom kategorije valentnosti (slov. vezljivosti) in kar je $s$ tem $v$ zvezi propozicionalno in modifikacijsko - valentnost pa je $v$ enem izmed osredij Tesnièrjeve pozornosti pri obravınavi skladenjskih vprašanj. V kakšnem razmerju so si torej Tesnièrjeve Osnove in Toporišičeva Slovnica (kakor v nadaljnjem krajšamo obe deli)?

Najprej je tu velika sorodnost $\mathrm{v}$ pojmovanju besednih vrst. Tudi jaz namreč nisem bil zadovoljen $s$ tradicionalnimi besednimi vrstami in sem za besednovrstno klasifikacijski merilo postavil primarno skladenjsko (stavčnočlensko) vlogo različnih besed. Tako sem že za svoj Slovenski knjižni jezik 1 (1965, napisano 1964) združil v eni besedni vrsti, imenovani pridevniška beseda (adjektival), tradicionalne pridevnike, sklonljive deležnike (pričujoč, obledel, tepen / ubit), števnike in ustrezne zaimke (n. d. 186: "pridevniške besede"). Na ta način so števniki postali števniški pridevniki, deležniki deležniški pridevniki itd. oz. zaradi izročila tudi drugače poimenovani (pridevniški zaimki). Zaimki so že tedaj (prim. SKJ 2, 1966) kot t. i. male množice v okviru samostalnika, pridevnika, prislova: "Zaimenske besede so, ki se uporabljajo namesto samostalnikov, pridevnikov in prislovov, znanih iz sobesedila ali govornega položaja". Enako sem pozneje (1974: Slovenski jezik, literatura in kultura, Informativni zbornik - Kratko oblikoslovje slovenskega knjižnega jezika) obravnaval tudi samostalniške zaimke kot delno množico samostalniške besede, pri čemer pa imam tudi jaz in ti za (sicer posebna) zaimka, prim. rod. $m e n e-m e=n j e g a-g a .-$ Vse to povsem ustreza Tesnièrjevi delitvi besednih vrst, npr. samostalnika na substantifs particuliers in substantifs généraux. Vendar sem jaz med polnopomenske besedne vrste 1974. uvedel tudi opisna deležnika na $-l$ in $-n /-t$ kot predikativa, katerih tipični reprezentant je npr. všec ali tiho (po načelu biti všeč = je delal / je delati / morati delati).

Med slovničnimi besedami sam jasno ločim (medmet) interjekcijo od (členka) partikule. Prvo in drugo je pri Tesnièrju zajeto v pojem beseda stavek, drugo pa deloma obravnavano tudi pri prislovu (posebna vrsta).

Po mojem tudi vodi pot od prirednega veznika $\mathrm{k}$ podrednemu in šele od tega $\mathrm{k}$ predlogu: Vem, pa ne povem $\rightarrow$ Čeprav vem, ne povem $\longrightarrow$ Kljub vedenju ne povem.

Pri vezljivosti (pri meni uvedena v objavi 1975/76) se od Osnov Slovnica loči po tem, da se tudi pri pasivizaciji drugoaktantska identiteta ohranja, prvoaktantska pa spreminja, ne pa da bi A 2 postal A 1, kakor je pri

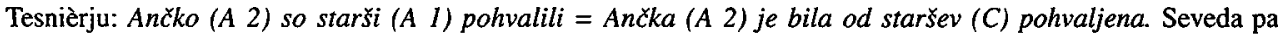
vezljivost razširjam tudi zunaj okvira pasivizacije na cirkumstante (npr. vstopiti $v$ razred) pa tudi $v$ pretvorbah (translacijah): Oče prihaja $\rightarrow$ prihod oceta $\rightarrow$ ocetov prihod. Itd. Translacije v okviru besednih vrst ločirn od skladenjskih (npr. (oče) nje $\rightarrow$ nje/n/ (oče) proti majhno dekle $\longrightarrow$ dekletce), pri čemer se strogo loči besedna zveza (govorna podstava) od tvorjene besede.

Seveda skladnja Slovnice tudi ne zanemarja naklonskosti, sorazmerno veliko skrb posveča členitvi po aktualnosti in obsega tudi stavčno fonetiko, od členitve s premori, prek težiščenja in stavčne intonacije, do registra in hitrosti ter glasovnega barvanja. Zlasti pri vprašanjih besednega in stavčnega reda seže (deloma tudi že $v$ skladnji povedi) preko okvira povedi $v$ besedilni odstavek. 